\title{
Estimating the impact of grazing industry on catchment nitrogen loads of the Moe River catchment
}

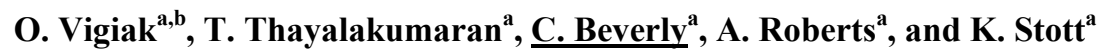 \\ ${ }^{a}$ Department of Environment and Primary Industries, Future Farming Systems Research Division, Victoria \\ ${ }^{b}$ Joint Research Centre of the European Commission, Institute for Environment and Sustainability, Ispra \\ (VA), Italy. \\ Email: olga.vigiak@jrc.ec.europa.eu
}

Abstract: Intensification of grazing industry management is a cause of concern as a potential source of nitrogen $(\mathrm{N})$ pollution at the catchment scale. To explore the impact of grazing industry and its management on $\mathrm{N}$ loads, a point-to-catchment approach was developed in this study. Point-scale $\mathrm{N}$ losses in leaching and runoff were estimated with two models, DairyMod and HowLeaky, for unique combinations of management, soil type, and climate (i.e. Hydrological Response Units, HRU). HRU N losses were divided in dissolved N (nitrate) in runoff, particulate $\mathrm{N}$ in runoff, and dissolved $\mathrm{N}$ in leached below the root-zone. The Catchment Scale Management of Distributed Sources Model (CatchMODS) was used to assess annual average nutrient budgets at the catchment scale. The spatial units were subcatchments, which comprised a river reach and the area (of about 20-60 $\mathrm{km}^{2}$ ) delivering water, sediment and nutrients to it. River reaches were connected to upstream and downstream reaches in a node-link system. Subcatchment annual average N loads in runoff were assigned proportionally to HRU area in each subcatchment, and adjusted for topography. $\mathrm{N}$ loads from leaching were estimated from subcatchment average monthly $\mathrm{N}$ concentration in the soil water below the root zone and the monthly volume of subsurface water reaching the stream; monthly loads were summed over the simulation period and divided by the number of years to get the annual average leached $\mathrm{N}$ load. Total $\mathrm{N}$ loads generated by streambank and gully erosion were estimated from erosion rates and $\mathrm{N}$ content of gully and streambank eroding walls. In-stream attenuation of total $\mathrm{N}$ was modeled as a first order decay exponential function, assuming an inverse relationship between in-stream removal and stream size. The model was applied to the Moe River catchment in West Gippsland to assess the impact of grazing management intensification on TN loads at the catchment outlet. The uncertainty in TN load predictions due to catchment model parameters was assessed with a Bayesian inference method, following the Flexible Model Environment (FME) procedure implemented in R. Sensitivity and identifiability analyses were conducted to screen sensitive parameters and identify parameter sets that could be concurrently assessed. A Markov-Chain Monte-Carlo (MCMC) analysis was conducted to obtain parameter sets conditioned on mean annual flow and average annual sediment and nutrient loads observed at the outlet. These conditioned model parameter sets were then used in Monte Carlo Simulations (MCS) to propagate model uncertainty in land use scenario analysis. Of the 15 initial catchment model parameters, four upscaling parameters that regulated transfer of water, sediment and nutrients from HRUs to the subcatchment could be successfully conditioned using water quantity and quality data observed at the outlet: the fraction of water surplus to stream discharge $F$; the hillslope sediment delivery ratio $S D R$, and the in-stream nutrient attenuation parameters. Of 5000 MCMC simulations, 3431 were accepted. The best posterior parameter set resulted in a TN load of about $440 \mathrm{t} \mathrm{TN} \mathrm{y}^{-1}$ at the outlet, which was very close to TN load estimated from monitoring station data $\left(430 \mathrm{t} \mathrm{TN} \mathrm{y}{ }^{-1}\right)$; TN sources largely coincided with areas dominated by dairy land use. The MCS runs showed that intensity of grazing management had a significant impact on TN loads: intensification of the dairy industry based on

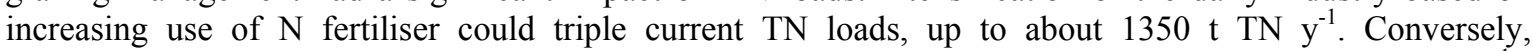
extensification (little or no use of $\mathrm{N}$ fertilizer) could reduce TN loads to about 30\% (i.e. 110-140 t TN y ${ }^{-1}$ ). Other sources of uncertainty, most notably uncertainties in point-scale model inputs and uncertainties in model structure, could also impact model predictions, but they could not be assessed because of insufficient data. However, because of their upscaling function, the four parameters that were assessed are believed to characterize most of model uncertainty, and may help buffer propagation of uncertainty from point-scale inputs. Notwithstanding the uncertainty in model results, grazing management intensity was identified as having a major impact on TN loads reaching the Moe River catchment outlet.

Keywords: $\quad$ Upscaling modeling, uncertainty analysis, Flexible Modelling Environment 
Vigiak O. et al., Estimating the impact of grazing industry on catchment nitrogen loads

\section{INTRODUCTION}

Intensification of grazing management via increasing farm nutrient imports and livestock density is a cause of concern as a potential source of nitrogen $(\mathrm{N})$ pollution in the environment. Assessing the impact of grazing management on water bodies requires an integrated approach to capture environmental and management conditions in paddocks that affect the amount and partitioning of nutrient losses in surface and subsurface pathways, as well as other nutrient sources and catchment attenuation processes which affect the nutrient loads of receiving waters.

The Gippsland Lakes are a large coastal lagoon system of international ecological significance that is threatened by eutrophication (Harris et al., 1998). Diffuse sources of nutrients from agricultural systems have been identified as major contributors to the excessive nutrient levels in the Lakes. The Moe River is a tributary of the Latrobe River, which is the largest contributor of water and nutrient loads to the Lakes. The Moe River catchment is dominated by dryland dairy systems and given the general trend of intensification of grazing industries, particularly dairy, it is important to assess the potential impact of such changes on the water quality of the river network and eventually to the Lakes.

The objective of this paper was to assess the potential impact of intensification of dairy industry on $\mathrm{N}$ loads reaching the Moe River catchment outlet. A point-to-catchment scale model was built to assess the average annual $\mathrm{N}$ budget of the catchment, accounting for environmental factors, management intensity, landscape nutrient sources and attenuation processes. Given the complexity of the model, an uncertainty analysis was conducted to assess the impact of catchment parameters - conditioned by water monitoring quality monitoring data, on $\mathrm{N}$ loads predicted for scenarios of differing grazing management intensity.

\section{THE MOE RIVER CATCHMENT}

The Moe River catchment area (with outlet at Victorian Water Quality monitoring station 226402, DSE 2012 ) is $577 \mathrm{~km}^{2}$. The western slopes are dominated by Ferrosols (25\% of catchment); the north-eastern slopes by texture contrast and some gradational soils (Chromosols and Dermosols; 43\%); whereas the southern slopes are dominated by texture contrast, sodic soils (Sodosols; $10 \%$ ). The main plain is dominated by Vertosols and Hydrosols (19\%). Forest and plantations occupy approximately $16 \%$ of the catchment area, dryland dairying $30 \%$, and a patchwork of beef enterprises intermixed with dairy enterprises $44 \%$ (Figure 1a). Based on $2006 \mathrm{ABS}$ census data and for the purposes of this study, this mixed dairy/beef land use was assumed to comprise $50 \%$ of beef enterprises and $50 \%$ of dryland dairying enterprises.

Grazing systems were defined based on local surveys and in consultation with district extension staff (Stott et al., 2013). The beef system was assumed to have no fertilizer $\mathrm{N}$ input and minimal supplementary feed. Four predominantly pasture-grazed dryland dairy systems were defined in terms of use of $\mathrm{N}$ in feed and chemical fertilizer, and milk production per unit area. The most intensive system (S-I) assumed $200 \mathrm{~kg} \mathrm{~N} / \mathrm{ha}$ fertilizer, $1.7 \mathrm{t} \mathrm{DM} \mathrm{(Dry} \mathrm{Matter)/cow} \mathrm{of} \mathrm{concentrate} \mathrm{fed,} \mathrm{and} \mathrm{produced} \mathrm{about} 990 \mathrm{~kg}$ Milk Solids (MS)/ha (2.1 cow $/ \mathrm{ha}$ stocking rate). The most extensive system (S-IV) assumed $35 \mathrm{~kg} \mathrm{~N} / \mathrm{ha}$ fertilizer, $1 \mathrm{t} \mathrm{DM} / \mathrm{cow}$ of concentrate fed, and produced about $410 \mathrm{~kg} \mathrm{MS} / \mathrm{ha}$ (1.3 cow/ha stocking rate). The other two systems were defined in between these two extremes. A fifth, 'advanced', alternative intensive system (S-A) was defined whereby milk production was increased by substituting chemical $\mathrm{N}$ fertilizer application to paddocks with greater capture and recycling of effluent waste and with supplementary feed to livestock. To explore the impact of changes in grazing management on $\mathrm{N}$ loads at the catchment outlet several land use scenarios were defined. The baseline scenario for current conditions assumed, based on expert local knowledge and census data, that dairy farming in the Moe catchment was composed of $10 \%$ of S-I, $30 \%$ of S-II, $40 \%$ of S-III, and $20 \%$ of SIV. The alternative scenarios were: DI - Dairy intensification under current practice (all dairy land use as SI); DE - Extensive dairying (all dairy land use as S-IV); DA - 'advanced' intensive dairying (all dairy land use as $\mathrm{S}-\mathrm{A}) ; \mathrm{B}-$ all grazing land use as beef.

\section{THE POINT-TO-CATCHMENT MODEL}

A point-to-catchment model developed for sediments and phosphorus (P) (Vigiak et al. 2011a; 2012) was expanded in this study to include modeling of total $\mathrm{N}$ load in the Moe River. Daily water, sediment and nutrient losses in runoff and leaching were estimated for Hydrologic Response Units (HRU), i.e. unique combinations of climate, soil, and land management, with two point-scale models (DairyMod and HowLeaky). The DairyMod model was used to simulate daily biomass cover and N losses in leaching; the HowLeaky model was used to simulate daily water, sediment and nutrient losses in runoff. Thayalakumaran et al. (2013) describe the coupling of the two models. 
Vigiak O. et al., Estimating the impact of grazing industry on catchment nitrogen loads

The catchment model was based on CatchMODS. The spatial units were subcatchments comprised of a river reach and the area (of about 20-60 $\mathrm{km}^{2}$, Figure 1a) delivering water, sediment and nutrients to the reach. River reaches were connected to upstream and downstream reaches in a node-link system. HRU losses were upscaled proportionally to their area in the subcatchment. Contributions from point sources, gullies and streambanks were added to subcatchment nutrient budget. Water, sediment, and P modeling are described in Vigiak et al. (2011a; 2012). Hereafter we briefly describe the extension of nutrient modeling to N.

\subsection{Nitrogen point-to-catchment model}

$\mathrm{N}$ modeling was developed broadly following the concepts used for P (Vigiak et al. 2012). HRU N losses were modeled as dissolved $\mathrm{N}$ (nitrate) in runoff $(D N)$, particulate $\mathrm{N}$ in runoff $(P N)$, and dissolved $\mathrm{N}$ leached below the root-zone $(L N)$. HRU daily $\mathrm{N}$ losses in runoff were summed for the simulation period and divided by the number of years of the simulation to get annual average dissolved $\mathrm{N}$ load $\left(D N_{\mathrm{HRU}}, \mathrm{kg} \mathrm{ha}^{-1} \mathrm{y}^{-1}\right)$ and particulate $\mathrm{N}$ load $\left(P N_{\mathrm{HRU}}, \mathrm{kg} \mathrm{ha}^{-1} \mathrm{y}^{-1}\right)$. Subcatchment $D N$ load $\left(D N_{S U B}, \mathrm{~kg} \mathrm{y}^{-1}\right)$ was the sum (for all HRUs of

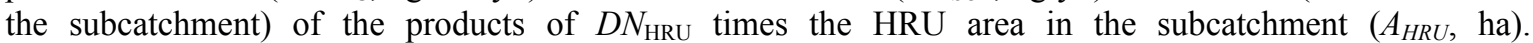
Subcatchment particulate $\mathrm{N}$ load $P N_{S U B}\left(\mathrm{~kg} \mathrm{y}^{-1}\right)$ was the sum (for all HRUs of the subcatchment) of the products of $P N_{\mathrm{HRU}}$ times $A_{H R U}$, adjusted for the subcatchment topography (by means of the Universal Soil Loss Equation LS factor, $L S_{\mathrm{SUB}}$ ), the hillslope sediment delivery ratio ( $S D R$, fraction), and the hillslope $\mathrm{N}$ enrichment ratio (NER, fraction, which in turn was a function of $S D R$ ):

$P N_{S U B}=S D R \cdot L S_{S U B} \cdot N E R \cdot \sum_{H R U \in S U B} P N_{H R U} A_{H R U}$

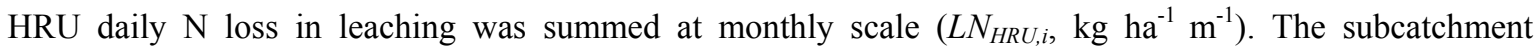
monthly average $\mathrm{N}$ concentration $\left(L C_{\mathrm{SUB}}, \mathrm{mg} \mathrm{L}^{-1}\right)$ in the drainage water (below the root zone) was assumed to be equal to the total monthly leached loads $(\mathrm{kg})$ divided by the monthly drainage volume $\left(D V_{i}, \mathrm{ML}\right)$ :

$L C_{S U B, i}=\sum_{H R U \in S U B} L N_{H R U, i} A_{H R U} / \sum_{H R U \in S U B} D V_{H R U, i} A_{H R U}$

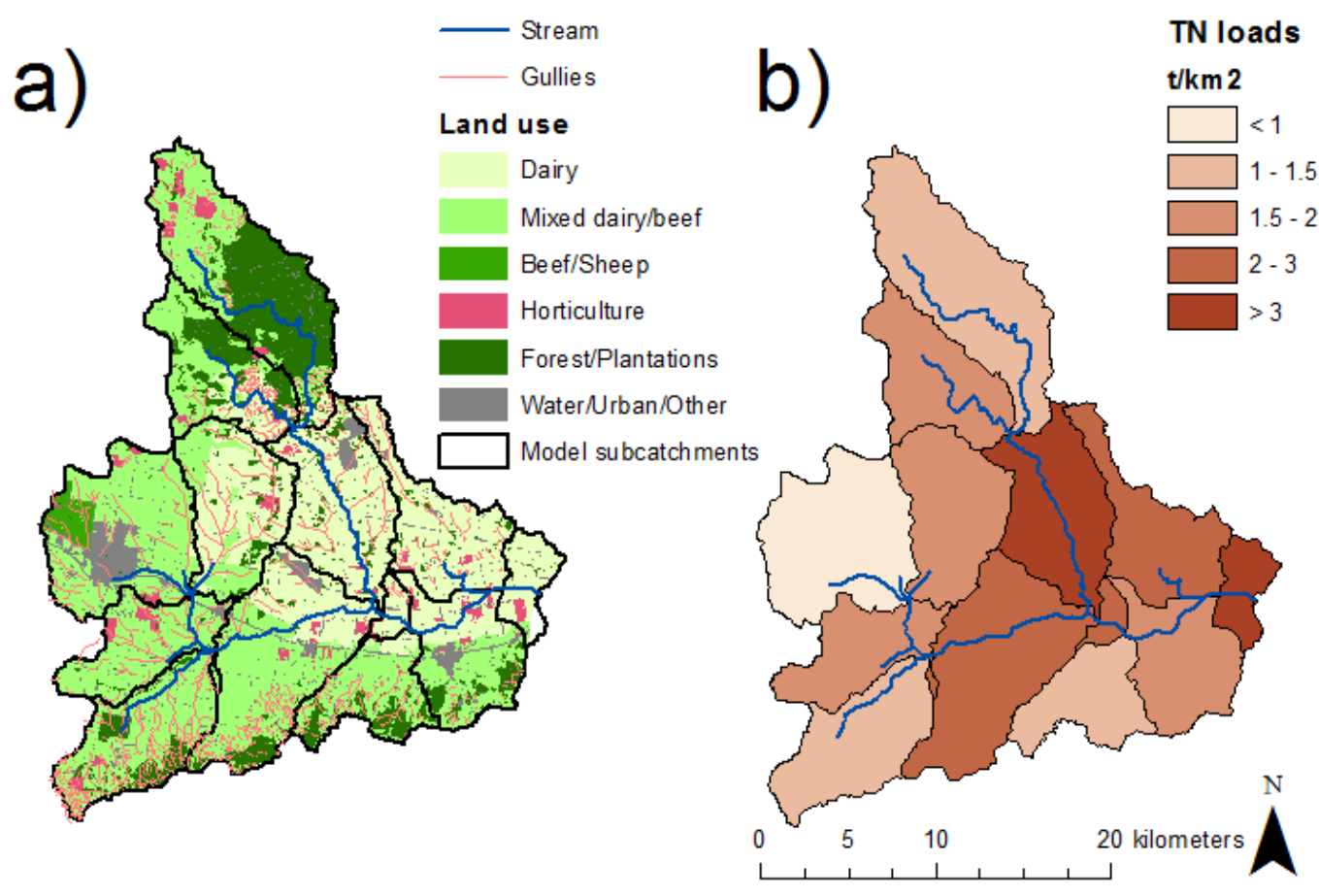

Figure 1. a) Moe River land use, and b) model TN load emission ( $\mathrm{t} \mathrm{km} \mathrm{y}^{-2} \mathrm{y}^{-1}$.

where the subscript $i$ indicates the month of the simulation period. The subcatchment monthly leached $\mathrm{N}$ load reaching the stream was equal to the monthly leached concentration by the minimum between the monthly slow flow generated in the subcatchment $\left(S F_{S U B, i}\right)$, and the subcatchment drainage volume (ML):

$L N_{S U B, i}=L C_{S U B, i} \cdot \min _{i}\left(S F_{S U B, i}, \sum_{S U B} D V_{H R U, i} A_{H R U}\right)$ 
Vigiak O. et al., Estimating the impact of grazing industry on catchment nitrogen loads

The subcatchment annual average leached load $\left(L N_{S U B}, \mathrm{~kg} \mathrm{y}^{-1}\right)$ was the sum of the monthly leached loads in the simulation period divided by the number of years of the simulation.

Total $\mathrm{N}$ loads generated by gully or streambank erosion $\left(T N_{G+S} ; \mathrm{kg} \mathrm{y}^{-1}\right)$ was calculated as:

$$
T N_{G+S}=10^{-6}\left(T N_{G} \frac{1}{\Delta_{G}} G_{S U B}+T N_{S} \frac{1}{\Delta_{S}} S_{S U B}\right)
$$

where $T N_{G}=$ total $\mathrm{N}$ content of gully wall $\left(\mathrm{mg} \mathrm{kg}^{-1}\right) ; \Delta_{G}=$ fraction of gully wall $(<63 \mu \mathrm{m})$ contributing to suspended sediments (i.e. all $\mathrm{N}$ content of the eroded walls was assumed to be attached to suspended sediments); $G_{S U B}=$ subcatchment annual suspended sediment load originated by gully erosion $\left(\mathrm{kg} \mathrm{y}^{-1}\right) ; T N_{S}=$ total $\mathrm{N}$ content of streambank wall $\left(\mathrm{mg} \mathrm{kg}^{-1}\right) ; \Delta_{S}=$ fraction of streambank wall contributing to suspended sediments; and $S_{S U B}=$ subcatchment suspended sediment load originated by streambank erosion $\left(\mathrm{kg} \mathrm{y}^{-1}\right)$.

Finally, the incoming subcatchment annual average total $\mathrm{N}\left(T N_{I N}, \mathrm{~kg}^{-1}\right)$ was equal to:

$T N_{I N}=\left(D N_{S U B}+P N_{S U B}+L N_{S U B}\right)+T N_{P}+T N_{G+S}+T N_{U P}$

where $T N_{P}\left(\mathrm{~kg} \mathrm{y}^{-1}\right)$ was total $\mathrm{N}$ load from point sources and $T N_{U P}\left(\mathrm{~kg} \mathrm{y}^{-1}\right)$ was the total $\mathrm{N}$ load received from the upstream areas.

In-stream total $\mathrm{N}$ attenuation was simulated as a first-order, exponential decay process. Assuming an inverse relationship between in-stream removal and stream size, attenuation was calculated as:

$\left.T N_{O U T} /_{T N_{I N}}=e^{\left({ }^{-z_{N} L S U B} / M A F S U B\right.}\right)$

where $z_{N}\left(\mathrm{ML} \mathrm{m}^{-1} \mathrm{y}^{-1}\right)$ is an in-stream attenuation parameter to be calibrated against total $\mathrm{N}$ observed at water quality monitoring stations, $L_{S U B}=$ reach length $(\mathrm{m})$, and $M A F_{S U B}=$ the reach Mean Annual Flow $\left(\mathrm{ML} \mathrm{y}^{-1}\right)$.

\subsection{Implementation in the Moe River and uncertainty analysis}

Water and sediment modeling for the larger Latrobe River catchment and landscape datasets are described in Vigiak et al. (2011b). P modeling based on Vigiak et al. (2012) was informed by data collected in the catchment. Thayalakumaran et al. (2013) describe the estimation of HRU daily N loads. $T N_{G}, \Delta_{G}, T N_{S}$, and $\Delta_{S}$ were estimated from 70 gully and streambank walls sampled in the catchment. The simulation period was 1990-1996; it was chosen because during this period land use could be considered stationary ('current') and annual rainfall $\left(1010 \mathrm{~mm} \mathrm{y}^{-1}\right)$ was close to long-term (1980-2000) average (940 $\left.\mathrm{mm} \mathrm{y}^{-1}\right)$, hence representative for the area.

Data for model calibration and uncertainty assessment consisted of monthly water discharge at the two gauging stations of the Moe River (stations 226209 and 226402 of the Victorian data Warehouse; DSE, 2012), and monthly nutrient concentration sampling for the outlet station 226402. Uncertainty in monthly discharge was small because there was no gap in daily discharge data. Conversely, annual average loads of total suspended sediments (TSS), total Nitrogen (TN), and total Phosphorus (TP) for the simulation period were estimated with rating curves based on daily discharge, and therefore subject to larger uncertainty.

Several uncertainty sources could affect model results including those attributable to imperfect knowledge and representation of processes; errors and simplifications in model structure; propagation of uncertainties in point-scale model inputs; spatial data; and catchment model parameters. Given the limited data available, uncertainty analysis focused only on catchment model parameters (Table 1) because (i) most of these parameters cannot be measured directly but are based solely on calibration; and (ii) their calibration may buffer uncertainties in other sources. 
Vigiak O. et al., Estimating the impact of grazing industry on catchment nitrogen loads

Table 1. Catchment model parameters used for the Moe River catchment uncertainty analysis.

\begin{tabular}{|c|c|c|c|}
\hline Parameter and function & Model output & Initial value & Tested range \\
\hline$F$ - Fraction of HRU excess water to discharge & Discharge, TSS, TN and TP & 1.2 & $1.1-1.3$ \\
\hline$V S$ - Volume of discharge slow flow & Discharge, TSS, TN and TP & 0.5 & $0.4-0.8$ \\
\hline$\alpha_{\mathrm{q}}-$ Quick flow routing & Discharge, TSS, TN and TP & -0.7 & $-0.6 ;-0.8$ \\
\hline$\alpha_{s}$ - Slow flow routing & Discharge, TSS, TN and TP & -0.98 & $-0.97 ;-0.99$ \\
\hline$S D R$-Sediment delivery ratio of hillslope erosion & TSS, TN and TP & 0.05 & $0.02-0.1$ \\
\hline $\begin{array}{l}\Delta_{G} \text { - Fraction of gully wall contributing to suspended } \\
\text { sediment load }\end{array}$ & TSS, TN and TP & 0.44 & $0.4-0.5$ \\
\hline $\begin{array}{l}\Delta_{S}-\text { Fraction of streambank wall contributing to } \\
\text { suspended sediment load }\end{array}$ & TSS, TN and TP & 0.64 & $0.6-0.7$ \\
\hline$b$ - Streambank erosion factor & TSS, TN and TP & 0.002 & $0.001-0.003$ \\
\hline $\begin{array}{l}v-\text { Setting velocity of suspended sediment particles } \\
(\mathrm{m} / \mathrm{s})\end{array}$ & TSS, TN and TP & 0.0001 & $0.00001-0.001$ \\
\hline$t$ - Recurrence time of overbank floods (year) & TSS, TN and TP & 2.5 & $2-3.5$ \\
\hline $\begin{array}{l}T P_{L}-\text { Total P content of gully/streambank walls } \\
(\mathrm{mg} / \mathrm{kg})\end{array}$ & $\mathrm{TP}$ & 450 & $400-600$ \\
\hline$z_{P}-$ in-stream attenuation of total $\mathrm{P}$ & $\mathrm{TP}$ & 4 & $2-6$ \\
\hline$T N_{G}-$ Total $\mathrm{N}$ content of gully walls $(\mathrm{mg} / \mathrm{kg})$ & TN & 2000 & $1800-2200$ \\
\hline$T N_{G}-$ Total N content of streambank walls $(\mathrm{mg} / \mathrm{kg})$ & $\mathrm{TN}$ & 1200 & $1000-1400$ \\
\hline$z_{N}-$ in-stream attenuation of total $\mathrm{N}$ & $\mathrm{TN}$ & 3 & $2-5$ \\
\hline
\end{tabular}

Model uncertainty was conditioned against available data using a Bayesian inference method implemented with the Flexible Model Environment (FME) package in R (Soetaert and Petzold, 2010). The FME uncertainty procedure consisted of four steps: 1) preliminary sensitivity analysis; 2) evaluation of the identifiability of parameters; 3) initial optimization of model simulations; and 4) Markov-Chain Monte Carlo (MCMC) simulation runs using the DRAM (Delayed Rejection Adaptive Metropolis) algorithm of the FME package. The sensitivity analysis allowed screening for the most sensitive parameters to bring forward in the analysis. The initial model parameters were set based on manual calibration and available measurements (Table 1). Given the pivotal role of discharge on model simulation, FME steps 1-3 were first applied to the four discharge parameters $\left(F, V S, \alpha_{\mathrm{q}}, \alpha_{\mathrm{s}}\right.$; Table 1) against monthly discharge (2 time-series of 84 entries); then FME steps 1-4 were applied to all parameters against Mean Annual Flow (MAF), TSS, TN and TP load at the outlet. Finally, conditioned model parameter sets were used in Monte Carlo Simulations (MCS, set to 500 runs) to propagate model uncertainty to land use scenario analysis.

\section{RESULTS AND DISCUSSION}

Monthly discharge was most sensitive to $F$ and $V S$, followed by $\alpha_{\mathrm{q}}$, while it was insensitive to $\alpha_{\mathrm{s}}$ in the plausible parameter range. While $F$ was uncorrelated to the other parameters, $V S$ was correlated to the two routing parameters $\alpha_{\mathrm{s}}$ and $\alpha_{\mathrm{q}}$. Parameter collinearity indicated that all four parameters could be identified concurrently; however, given the insensitivity of $\alpha_{\mathrm{s}}$, only $F, V S$, and $\alpha_{\mathrm{q}}$ were optimized, resulting in the initial dataset of: $F=1.06, V S=0.74, \alpha_{\mathrm{q}}=-0.65$.

Model MAF, sediment and nutrient loads were most sensitive to $F, S D R, z_{P}$ and $z_{N}$. These parameters regulate transfer of water, sediment and nutrient from HRU to subcatchments, and in-stream attenuation. Outputs were also sensitive to $V S, \alpha_{\mathrm{q}}, \Delta_{s}$, and $b$ but to a lesser extent. $\Delta_{s}$ and $b$ were highly correlated: they both regulated streambank erosion, a major source of sediment in the Moe River. Conversely, gully erosion or floodplain deposition parameters $\left(\Delta_{G}, v\right.$ and $\left.t\right)$ were insensitive; these were minor processes in the catchment. $T N_{S}$ and $T N_{G}$ were insensitive but correlated to $z_{N}$. Collinearity analysis indicated that only four parameters could be concurrently identified with the available data; $F, z_{P}, z_{N}$, in combination with either $S D R$ or $b$. Given that $S D R$ regulated HRU upscaling of sediments, parameter $b$ was dropped in favor of $S D R$. 
Optimization of the model yielded the initial parameter set for MCMC simulation $\left(F=1.28, S D R=0.077 ; z_{P}=\right.$ $\left.4.60 ; z_{N}=3.43\right)$ and the parameter variance-covariance matrix. Prior parameter distributions were set as uniform in large ranges $(F=[0.95-1.45]$; $S D R=[0.04-0.12] ; z_{P}=[2.75-7] ;$ and $z_{N}$ $=[1.5-4.5])$. MCMC DRAM runs were set to 5000 , with delayed rejection of 2 updating every 50 runs. There was no burn-in period because simulation started from an optimized initial set. In total, 3431 MCMC simulations were accepted. Visual inspection of parameter traces indicated that convergence was achieved. The posterior $95 \%$ credible intervals were: $F=$ [1.06-1.41]; $S D R=$ $[0.053-0.11] ; z_{P}=[3.46-5.91]$, and $z_{N}$ $=[2.38-4.23]$. Posterior distributions showed positive correlation between $F$ and $z_{P}$, and between $F$ and $z_{N}$ (Figure 2). The application of the best posterior parameter set yielded about $440 \mathrm{t} \mathrm{TN} \mathrm{y}^{-1}$, which was very close to the rating curve estimation (430 t TN $\left.\mathrm{y}^{-1}\right)$; TN sources largely coincided with areas dominated

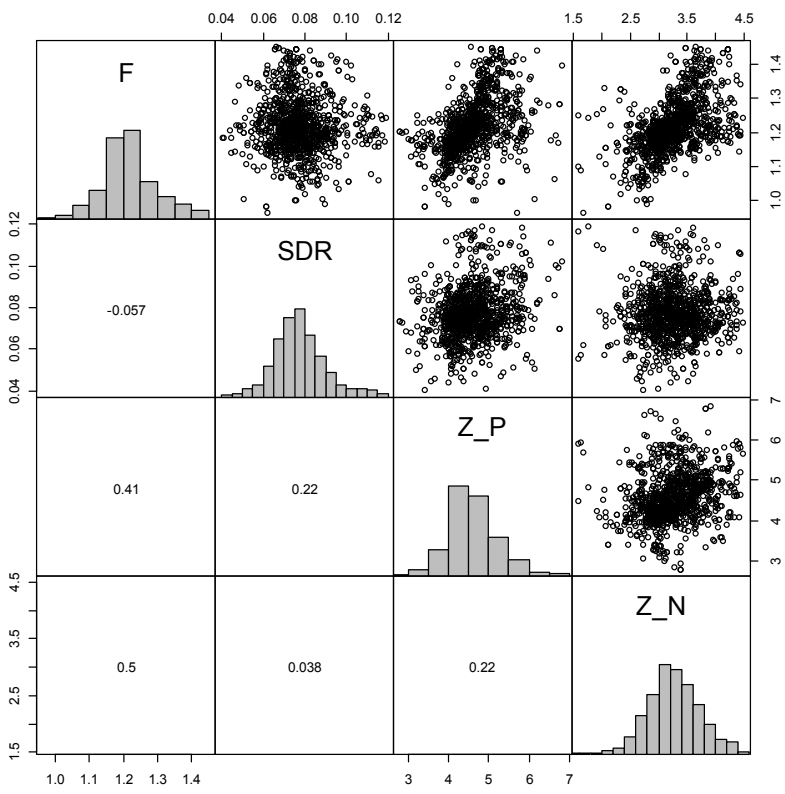

Figure 2. Posterior model parameter sets: histograms (on diagonal); scatter plots (upper-right); and parameter correlations (lower-left). by dairy land use (Figure $1 b$ ).

Propagation of model uncertainty to scenario predictions with MCS runs showed that intensity of grazing management had a significant impact on TN loads (Figure 3). Intensification of dairy industry (scenario DI) could triple current TN loads, up to about $1350 \mathrm{t} \mathrm{TN} \mathrm{y}^{-1}$. Conversely, the more extensive systems (scenarios $\mathrm{DE}$ and $\mathrm{B}$ ) could reduce current $\mathrm{TN}$ loads by about 70\% (to 110-140 t $\mathrm{TN} \mathrm{y}^{-1}$ ). The 'advanced' intensive system (DA) could achieve similar milk production as DI whilst increasing current TN loads by a more moderate $40 \%$.

Other sources of uncertainty, most notably uncertainties in point-scale model inputs and uncertainties in model structure, could also impact model predictions. A sensitivity analysis of DairyMod and HowLeaky (Thayalakumaran et al., 2013) highlighted several co-dependencies in point-scale inputs; for example, runoff and deep drainage volumes were negatively correlated, while $\mathrm{N}$ loss in leaching was positively correlated to drainage volume, and negatively correlated to $\mathrm{N}$ loss in runoff. Propagation of uncertainty of point-scale inputs to catchment-scale outputs would require a full characterization of these dependencies. Unfortunately, data availability was insufficient to even account for all catchment-scale parameters; for example, $S D R$ and $b$ parameters could not be concurrently identified; thus uncertainties between hillslope and streambank sources

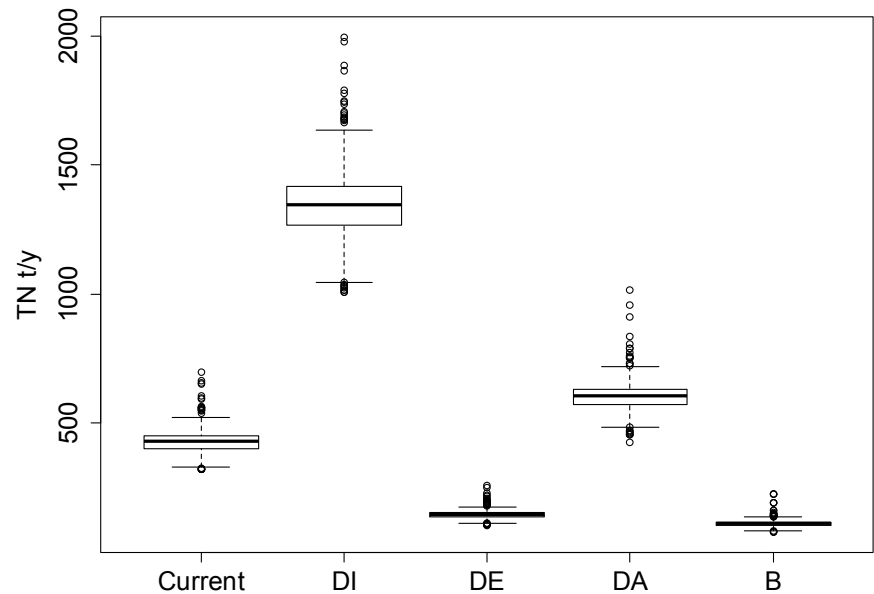

Figure 3. TN load (t/y) estimated for different scenarios with uncertainty: Current = current conditions; DI = intensive dairy system; DE = extensive dairy system; DA = advanced intensive dairy system; B = beef system. The boxplot indicates median output of $500 \mathrm{MCS}$ (thick line), the interquartile range (limits of box), 1.5 the interquartile range (whiskers) and simulation outside these limits (circles). 
remained un-assessed. However, as $\mathrm{N}$ losses from agricultural land accounted for more than 95\% of TN load at the outlet, impact of this uncertainty is presumably small. Structural uncertainties (i.e. due to model specifications) may also be important, particularly the transfer of $\mathrm{N}$ loads in leaching to stream (eq. 3 ) and instream attenuation (eq. 6), which does not account for reach physical conditions. The model assumes a monthly equilibrium between $\mathrm{N}$ concentration in subsurface flow and slow flow; this seems reasonable for the Moe River catchment, which is relatively small and well connected to the stream, but longer time lags should be expected in other environments. Eq. 6 quantifies 'apparent' rather than 'real' in-stream attenuation, i.e. it inherently corrects for errors in estimation of $\mathrm{N}$ load at the source. Such structural uncertainties can only be quantified (and reduced) by improving the knowledge of the system. Despite these limitations, the four most sensitive parameters $\left(F, S D R, z_{P}\right.$, and $\left.z_{N}\right)$ could be successfully conditioned against available data. Because of their functions, these parameters are believed to include the most important sources of uncertainty in model outputs, buffering uncertainties in model inputs and structure.

Notwithstanding the uncert-ainty in model parameters, grazing management intensity was identified as having a major impact on TN loads reaching the Moe River catchment outlet. Current trends toward intensification of dairy systems may thus lead to significant increase of environmental stress in the Gippsland Lakes. Innovative intensive systems may reduce potential trade-offs between agricultural income, milk production, and the environment, compared with conventional approaches to intensification (increased fertilizer use). However, even with such innovative approaches, $\mathrm{N}$ loads would still be $40 \%$ higher than current loads.

\section{ACKNOWLEDGMENTS}

We would like to thank Mr Sorn Norng (DEPI Victoria) for assistance in interpretation of uncertainty analysis results; and Mr Peter Manger and Mr Andrew Hicks (ANU, Canberra) for help in coding CatchMODS model in the R language.

\section{REFERENCES}

Department of Sustainable Environment (DSE) of Victoria (2012). Victorian Water Resources Data Warehouse. http://www.vicwaterdata.net/vicwaterdata/ [accessed 27.03.2012]

Harris, G., Batley, G., Webster, I., Molloy, R., Fox, D. (1998). Gippsland Lakes Environmental Audit: Review of water quality and status of the aquatic ecosystems of the Gippsland Lakes. CSIRO Environmental Projects Office. http://www.gcb.vic.gov.au/publications/csiro/CSIRO1998.pdf [accessed 18.07.2013]

Soetaert, K., and Petzold, T. 2010. Inverse modeling, sensitivity, and Monte Carlo analysis in R using FME package. Journal of Statistical Software, 33, 1-28.

Stott, K., O’Brien, G., Kumaran, T., Vigiak, O., Rees, D., Shambrook, D., and Roberts, A. (2013). Development of representative farming systems for the Moe River catchment. FFSR Technical Report. Department of Environment and Primary Industries, Parkville.

Thayalakumaran T., Vigiak O. Beverly, C., Roberts, A., Robinson, B, and Freebairn, D. (2013). Integrating two process based models for assessing dairy system management impacts on N losses. MODSIM2013 Modelling and Simulation Society of Australia and New Zealand, Adelaide, Australia 1-6 December 2013.

Vigiak, O., Newham, L.T.H., Whitford, J., Roberts, A.M., Rattray, D., Melland, A.R. (2011a). Integrating farming systems and landscape processes to assess management impacts on suspended sediment loads. Environmental Modelling and Software, 26, 144-162.

Vigiak, O., McInnes, J., Beverly, C., Thompson, C., Rees, D., Borselli, L., (2011b). Impact of soil erodibility factor estimation on the distribution of sediment loads: the LaTrobe River catchment case study. In Chan, F., Marinova, D., Anderssen, R.S. (eds) MODSIM2011 19th International congress on modelling and simulation. Modelling and Simulation Society of Australia and New Zealand, Perth, Australia 12-16 December 2011, 1930-1936. [http://www.mssanz.org.au/modsim2011/E3/vigiak.pdf]

Vigiak O., Rattray, D., McInnes, J., Newham, L.T.H., Roberts, A.M. (2012). Modelling catchment management impact on in-stream phosphorus loads in Northern Victoria. Journal of Environmental Management, 110, 115-125. 